\title{
Gas-to-aqueous Phase Transfer for Three Paint Solvents Injected into an Abiotic, Industrial Biotrickling Filter Measured with a Flame Ionization Detector
}

\author{
Ludwig Gredmaier ${ }^{1 *}$, Sabine Grüner-Lempart ${ }^{1}$, Julian Eckert ${ }^{1}$, Rainer Joachim² ${ }^{2}$ Peter Funke ${ }^{2}$ \\ ${ }^{1}$ Department of Bioengineering Sciences, Weihenstephan-Triesdorf University of Applied Sciences, 85354 Freising, \\ Am Hofgarten 10, Germany \\ 2 IDS Ltd., 83714 Miesbach, Müller am Baum 9, Germany \\ * Corresponding author, e-mail: ludwig.gredmaier@web.de
}

Received: 17 April 2021, Accepted: 01 July 2021, Published online: 18 October 2021

\begin{abstract}
This is a knowledge contribution to the unsatisfactory biodegradation problem, when biotrickling filters are purifying mixed paint solvents. A biotrickling filter manufacturer reported low biodegradation rates during the purification of a hydrocarbon pollutant mix from an industrial paint spraying floor. From a gas chromatograph/mass spectrometer analysis both hydrophilic and hydrophobic solvents were found in the polluted air. It is known that biodegradation is retarded, if the pollutant does not transfer from gas to liquid into the biofilm and it was therefore suspected that hydrophobic pollutants do not sufficiently migrate into the water/biofilm. To test this hypothesis, pure, rather than mixed pollutants, were injected into the abiotic biotrickling filter. When hydrophobic paint solvent (xylene) was sprayed into the biotrickling filter, the solvent load at the outlet of the filter was almost as high as at the inlet. But when pure, hydrophilic paint solvent (PGME) was sprayed into the abiotic biotrickling filter, the solvent load measured at the outlet of the filter was zero, indicating complete dissolution into the circulation water. Carbon/solvent loads at the filter outlet and inlet were measured with a portable flame ionization detector instrument. The experiment confirms that the hydrophobic solvent does not migrate into the liquid phase. This poor mass transfer of hydrophobic solvents is likely to be the reason for the low biodegradation rate. The result is highly relevant to the paint spraying industry and manufacturers of exhaust gas treatment equipment alike, who spend millions in non-sustainable incineration of exhaust gases.
\end{abstract}

\section{Keywords}

biotrickling filter, bioremediation, aromatic solvent, hydrophobic, hydrophilic, volatile organic compound

\section{Introduction}

Biological treatment of waste gases with biofilters is an area of interest due to low cost, low maintenance, and high sustainability through non-toxic end products/byproducts during operation. Biotrickling filters represent a subclass of biofilters, that recirculate water to provide a humid environment that promotes biofilm development. Biofilters can also sometimes be irrigated, but at a much lower level than biotrickling filters, and typically contain organic, rather than artificial or mineral carrier material. Biotrickling filters have successfully been employed to treat waste gases for decades and have become standard practice in several industry sectors such as

- the treatment of exhaust gases from the painting and coating industry [1]. Similarly, in the treatment of methyl ethyl ketone, toluene, n-butyl acetate and o-xylene (MTBX) from the paint spray industry very high removal rates can be achieved if the pollutant loading is under $120 \mathrm{~g}$ [2];

- in agriculture with the treatment of livestock ammonia emissions [3-5];

- the automotive industry where the treatment of a mix of non-aromatic pollutants (2-ethyl hexyl acetate, methyl isobutyl ketone and methyl ethyl ketone) in a factory that produces cylinder head gaskets, where a removal rate of almost $93 \%$ was achieved [6].

Many more examples can be found in a number of biofilter reviews [7-12]. Despite the success of biotrickling filters, situations exist, where satisfactory levels of exhaust gas purification could not be achieved. In particular, 
exhaust gases containing certain VOC (volatile organic compound) mixtures can be recalcitrant to bioremediation [13-17]. An industrial scale biofilter was inadequate for the degradation of VOCs from dip spin coating of metallic components, where the pollutants consisted of hydrophilic methoxypropyl acetate and hydrophobic xylene isomers. In this case removal efficiencies were below $20 \%$ [18]. Similarly, the pharmaceutical industry encountered difficulties treating mixed VOC exhaust gases $[19,20]$. And a mix of paint spray exhaust containing benzene, toluene and xylene (BTX) is considered difficult to biodegrade, unless an appropriate microbial community is inocculated [21]. Even though degradation of single, aromatic VOCs is possible [21], this may not be so if other, more microbially accessible VOCs are present at the same time. When two alcohols and an ether are simultaneously present in the exhaust air, the ether (ethoxy-2-propanol) is much harder to degrade than the two alcohols due to catabolite repression [22]. Similarly, methyl ethyl ketone (MEK) and methyl iso-butyl ketone (MIBK) from the paint spray industry are well degradable when present alone. But if both pollutants are present in the exhaust gas, competitive inhibition of one substrate/pollutant over the other can be a problem [23]. In addition, longer EBRTs (empty bed residence times) are required to degrade aromatic VOCs compared to non-aromatic, oxygenated VOCs. The removal of styrene required comparatively long EBRTs from 31 to $66 \mathrm{~s}$ and the biotrickling filter took 300 days to reach full performance [24]. When the exhaust from an industrial wood painting shop floor was treated with a full scale biotrickling filter, low degradation of aromatic solvents was encountered and long EBRTs in the order of $85 \mathrm{~s}$ were required for the aromatic components to biodegrade [25]. Similarly, the treatment of a pollutant mix (methyl ethyl ketone, toluene, n-butyl acetate and o-xylene) from the paint spray industry required long EBRTs of $42 \mathrm{~s}$ [2], who report that nonaromatic pollutants are easier to degrade than aromatic ortho-xylene. Yet, treating a mixture of VOCs simultaneously present in the exhaust stream is paramount, when emissions from industrial paint shop floors need to be purified [26]. In general, mixed VOCs from paint spray booths frequently contain two classes of solvents - oxygenated, non-aromatic solvents (such as esters, alcohols and in some cases ketones) and aromatic hydrocarbons. In summary, the bioremediation of exhaust air containing a mixture of esters/acetates and aromatic solvents such as butyl acetate and xylene isomers, can be difficult for two reasons:
1. biological recalcitrance: Microorganisms resident on the surface biofilm of the carrier material prefer to degrade oxygenated, non-aromatic over aromatic solvents $[15,17,27-29]$. The term given to the phenomenon of preferred microbial metabolism/catabolism on one substrate rather than another, is known as diauxie [30]. Microorganisms tune their enzyme machinery to the carbon source and tend to access different carbon sources in a certain order rather than simultaneously [31-33]. Due to the preference of certain solvents over others, their degradation can be impaired, if mixed oxygenated and aromatic VOCs are treated in biofilters at the same time. Newer degradation approaches including ozone oxidation attempt to overcome difficulties with recalcitrant pollutants in the painting and coating industry [34].

2. physico-chemical gas-to-aqueous phase transfer: The catabolism of solvents such as butyl acetate and xylene in exhaust air requires the migration from the gaseous phase into the aqueous phase in a biotrickling filter [35-37]. Yet solvents frequently exhibit a very wide range of gas-to-liquid mass transfer capabilities. It is clear that solvents with low transfer into the aqueous phase are harder to degrade than solvents with a high transfer rate [38]. In particular, non-polar solvents such as xylene, hardly migrate into the aqueous phase.

The experiments reported here, purely deal with the latter problem, i.e. the transfer from gas to the aqueous phase of the three solvents xylene, butyl acetate, and PGME (propylene glycol methyl ether; IUPAC: 1-methoxy-2-propanol). If a hydrophobic solvent is injected into a biotrickling filter with biofilm present, and this solvent is not sufficiently eliminated at the filter outlet, then the problem can either be caused by biological recalcitrance or inadequate gas-to-aqueous phase transfer. If biofilm is present in a functional biofilter, both explanations are equally possible. Either a lack of biological degradation or a lack of gas-to-aqueous phase mass transfer can be responsible for low pollutant elimination - it is not possible to point the finger at the culprit. Low gas-to-water mass transfer of pollutants was observed in laboratory reactors before $[38,39]$, but has never been investigated on an industrial scale biotrickling filter. One could argue, that gas-to-aqueous phase transfer improves, if a hydrophobic solvent is forced through the dense lava rock packing material under a powerful fan. The research question therefore can be 
stated: Is gas-to-aqueous phase transfer of hydrophobic solvents under a forced regime also a problem in an industrial sized biotrickling filter?

\section{Materials and methods}

To answer this gas-to-aqueous phase transfer question, pure rather than mixed solvents were injected into the abiotic biotrickling filter and the carbon content at the output was measured and related to the input level. An existing, industrial scale biotrickling filter designed to treat exhaust air from an industrial paint shop floor that is coating plastic parts, was used in all experiments as shown in the left-hand side of Fig. 1. The filter is driven by a large fan assembly feeding exhaust air into the tower. The tower of the biotrickling filter is $3.5 \mathrm{~m}$ in diameter and $4.4 \mathrm{~m}$ high which amounts to a filter volume of approximately $53 \mathrm{~m}^{3}$. The packing volume is $42 \mathrm{~m}^{3}$ (carrier volume including void spaces), and with an exhaust gas flow rate of $15000 \mathrm{~m}^{3} \mathrm{~h}^{-1}$ the $\mathrm{EBRT}=$ packing volume/exhaust gas flow rate $=$ $42 \mathrm{~m}^{3} / 4.17 \mathrm{~m}^{3} \mathrm{~s}^{-1}=10 \mathrm{~s}$. This is a comparatively low value, particularly in view of the presence of aromatic VOCs, that frequently requires longer EBRTs. The biotrickling filter contains lava rock as carrier material for the biofilm to ensure longevity. Three layers of lava rock gravel are used: Small sized lava rock gravel is located in the lowest part of the tower, medium sized lava rock in the middle and large sized lava rock gravel at the top of the tower in roughly equal amounts as illustrated in the right-hand side of Fig. 1. For all experiments the exhaust feed from the paint shop floor was disconnected and ambient air was driven through the filter. The biotrickling filter was cleaned/washed from all biofilm/microorganisms beforehand to eliminate biological degradation in the experiments. Absence of biological

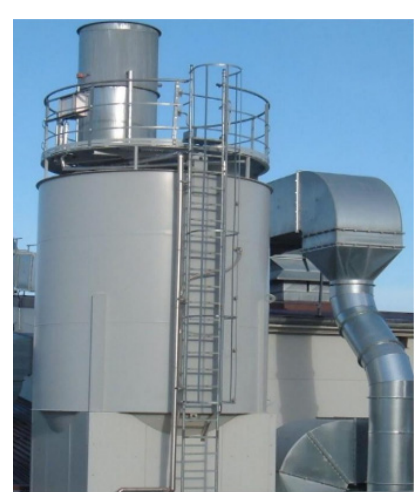

(a)

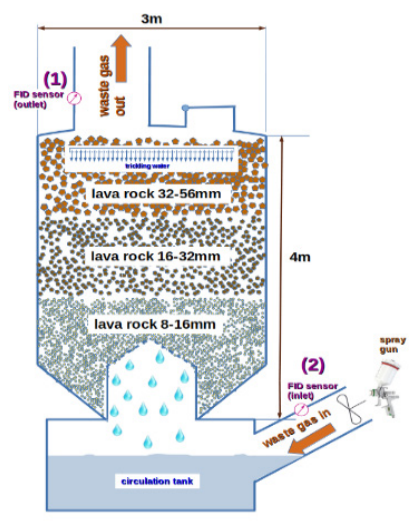

(b)
Fig. 1 (a) Industrial sized biotrickling filter used for the treatment of VOCs; (b) Sketch with FID (flame ionization detector) positions (1) at the outlet and (2) at the inlet of the filter degradation was confirmed with an infrared-based $\mathrm{CO}_{2}$ meter. Levels of $\mathrm{CO}_{2}$ inside the filter were identical to ambient levels (data not shown).

\subsection{Choice of solvents}

The pure solvent injection experiment was carried out three times - each time with a different solvent commonly used in paintings and coatings. The three solvents were of industrial grade and were supplied by Warnecke and Böhm Ltd. [40]:

- xylene (isomer mix): A frequently used solvent for paint thinners and main coatings. Water solubilities of the three xylene isomers are 156, 146 and $170 \mathrm{mg}$ per liter for para-, meta- and ortho-xylene respectively [41]. For a xylene isomer mix Henry's law solubility constant is approximately $0.002 \mathrm{molm}^{-3} \mathrm{~Pa}^{-1}$ (values for ortho-xylene range from 0.0010 to $0.0024 \mathrm{molm}^{-3} \mathrm{~Pa}^{-1}$, meta-xylene 0.0006 to $0.0018 \mathrm{molm}^{-3} \mathrm{~Pa}^{-1}$, para-xylene from 0.001 to $0.002 \mathrm{molm}^{-3} \mathrm{~Pa}^{-1}$ after [42]). Xylenes are well known for their hydrophobic behavior.

- butyl acetate: Frequently used in paint thinners and main coatings. Water solubility is $4.3 \mathrm{~g}$ per liter [43] i.e., considerably higher than for xylene. Henry's law solubility constant amounts to approximately $0.028 \mathrm{molm}^{-3} \mathrm{~Pa}^{-1}$ with a range of values from 0.021 to $0.035 \mathrm{molm}^{-3} \mathrm{~Pa}^{-1}$ after [42].

- PGME/1-methoxy-2-propanol: Used in standard paint thinners. PGME is fully soluble in water [44] and comes with a high Henry's law solubility constant between 1.1 to $4.8 \mathrm{molm}^{-3} \mathrm{~Pa}^{-1}$ [42].

The three solvents were chosen due to their widely differing Henry's law solubility constants and water solubilities.

\subsection{Abiotic operation of the filter}

Even though the biotrickling filter was previously functional, it has been cleaned thoroughly and did not carry biofilm during the injection experiments. All experiments were carried out with an abiotic filter (in absence of biological degradation) but with trickling water present. The idea is to observe the degree of dissolution of the three solvents into the aqueous phase and eliminating any effects from microbial biodegradation. The biotrickling filter was continuously irrigated with circulating water from the top of the tower in the weeks before the experiment and also during the solvent injection experiments with a 
continuous, constant water flow rate of 100 liters per minute. Ambient air (i.e. not exhaust air from the paint shop floor) was blown through the tower $\left(15000 \mathrm{~m}^{3} \mathrm{~h}^{-1}\right)$ during the injection experiment. If a high concentration of solvent is measured at the filter outlet under this constellation, it is clear that no or only little mass transfer into the aqueous phase is taking place inside the filter.

\subsection{Injection procedure}

The solvent (either butyl acetate, xylene, or PGME) was injected for 5 minutes with subsequent 10-minute breaks in a time pattern depicted in Fig. 2. Every solvent was individually injected into the gas inlet duct of the biotrickling filter using a standard pneumatic spray painting gun as shown in Fig. 3. The spray gun always contained $500 \mathrm{ml}$ of liquid solvent which was sprayed into the inlet duct in one go during the 5-minute injection intervals. After the 5-minute long, continuous injection, the spray gun was refilled manually during the 10-minute break. All injection experiments with the three chosen solvents were carried out in the $2^{\text {nd }}$ half of 2019 on different days with several weeks between measurements. Apart from the last experiment with PGME, the circulation liquid was renewed before each injection. A spray gun "Sata jet 1000 BRP" from [45] was used to inject the three solvents into the inlet air duct of the biotrickling filter (Fig. 3).

\subsection{Circulation liquid}

A stainless steel reservoir-type circulation liquid tank is located under the actual biotrickling filter underneath the tower. The tank contains about 1500 litres of tap water (Fig. 1). In the two injection experiments with butyl acetate and xylene the old circulation liquid was drained and fresh tap water was filled into the circulation tank before the injection experiment. Only for the third injection experiment with PGME solvent, the circulation liquid was not replaced and therefore contained minute traces of xylene from the previous xylene injection experiment carried out 10 weeks ago.

\subsection{Flame Ionization Detection (FID) instrument}

A flame ionization detector responds to carbon content in an analyte gas [46]. The carbon atoms in the analyte gas are burnt in a hydrogen flame and the gas is ionised, i.e., electrically charged particles produce a current. This current is amplified and measured. The higher the current the higher the carbon concentration in the analyte gas. In simple terms, a FID is a carbon counter/ion counter that responds to unoxidised carbon atoms in the hydrocarbon analyte gas [47-49]. A portable flame ionization detector 'ErsaTec SmartFID', with software version V1.120605k, built in 2014 (Fig. 4, [50]), was used to measure carbon content at the inlet and outlet of the biotrickling filter. No attempt was made to compare absolute carbon content $\left[\mathrm{mg}\right.$ of carbon per $\mathrm{m}^{3}$ ] between the three chosen solvents to avoid having to determine the response factor for each gaseous solvent for the ErsaTec FID instrument. Instead, the amplitudes for each solvent at the inlet and outlet of the biotrickling filter were used to compute the amplitude ratio between peak inlet and outlet levels during the injection with Eq. (1). The highest value of the FID signal at the outlet was taken as the outlet amplitude, and the highest value of the FID signal at the inlet (four pulses) was taken as the inlet amplitude - see horizontal lines in Fig. 5. The FID measurements were made at the filter outlet and filter inlet and the two measurement locations are depicted in Fig. 1 as positions (1) and (2), respectively. The sampling rate of the instrument was one measurement every five seconds. The ErsaTec FID meter was calibrated according to the manufacturer's instructions with a calibration gas cartridge supplied by Calgaz [51] (Newcastle-under-Lyme, U.K.) that contained 100.3 ppm of iso-butylen in artificial air. Only one FID instrument was available, hence measurements at the inlet and outlet of the biotrickling filter had to be carried out in succession rather than simultaneously. For the FID ampliude response at the biofilter inlet only a single 5-minute long solvent pulse was injected (to reduce solvent use) as shown

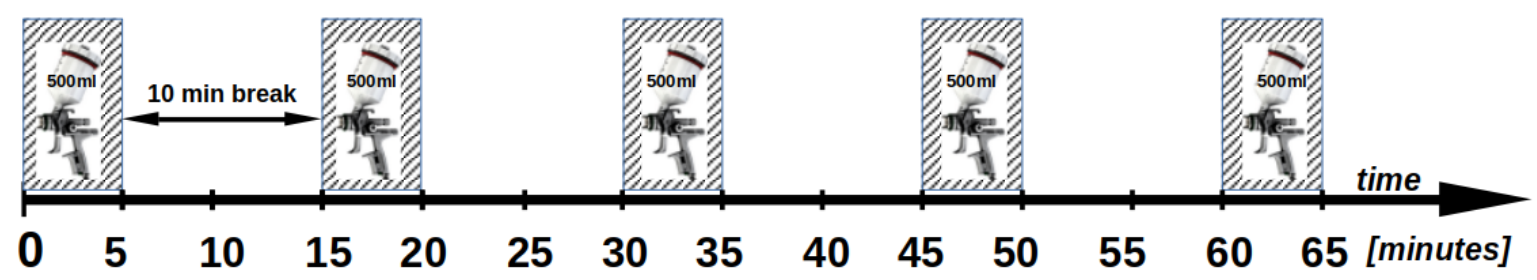

Fig. 2 Five-minute long injection intervals with ten-minute breaks in between. This spray pattern was used with the FID instrument at the output. When the FID instrument was located at the filter input only a single pulse was sprayed into the filter to save solvent 

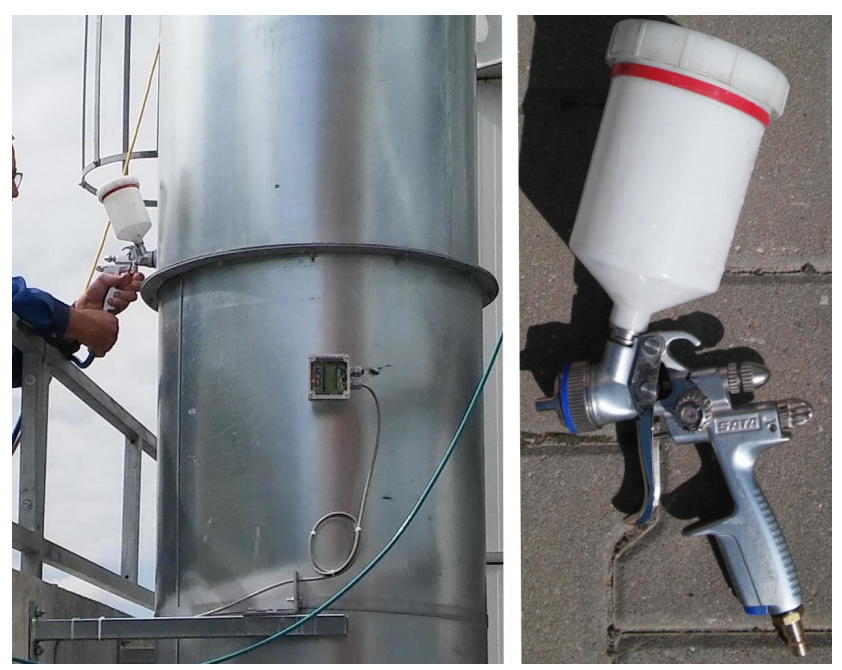

Fig. 3 Injection of $500 \mathrm{ml}$ pure solvent into the filter inlet duct
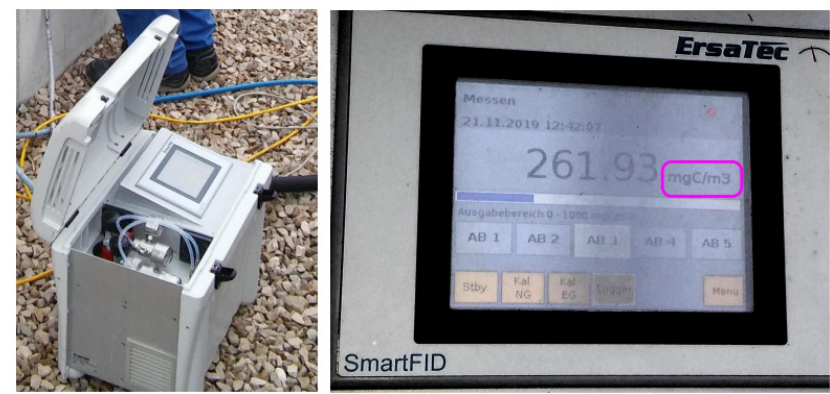

Fig. 4 An "ErsaTec SmartFID" from [50] measured gaseous carbon content at the outlet and inlet of the biotrickling filter during the solvent injection experiments

by the red graphs in Fig. 5, whereas for the FID measurements at the filter outlet, four or five injection pulses were used, mainly because of the more fluctuating FID signal at the outlet (green graphs in Fig. 5). During the injection of a particular solvent into the inlet duct of the biotrickling filter, the maximum value (peak) of the FID signal ampltitude at the outlet divided by the maximum value (peak) FID signal at the inlet was used to compute the amplitude ratio. Taking the peak average (rather than the maximum peak value) would equally be possible and gives similar results. The amplitude ratio between output and input FID signal can be used to compute the (percentage) fraction of the input solvent exiting the filter:

\%age solvent exiting the filter

$=\frac{\text { FID peak amplitude at outlet }}{\text { FID peak amplitude at inlet }} \times 100$.

Eq. (1) was used to compute the percentage of the solvent exiting the filter for the three chosen solvents and to produce Fig. 6.

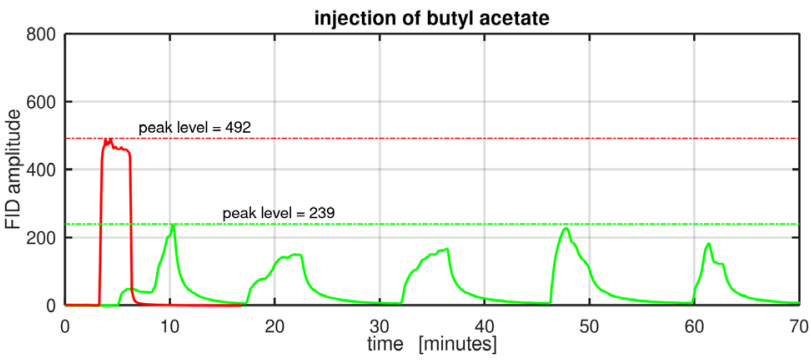

(a)

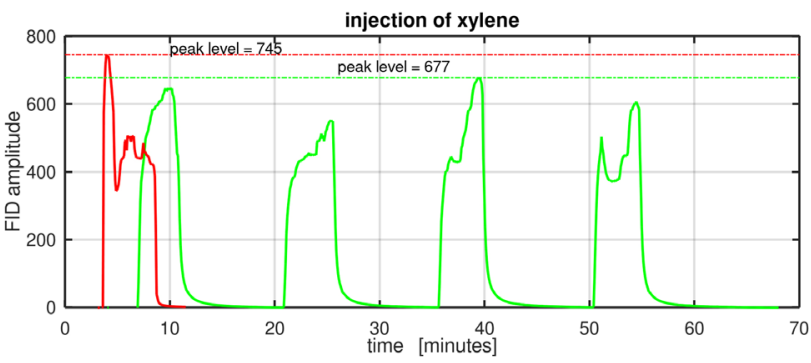

(b)

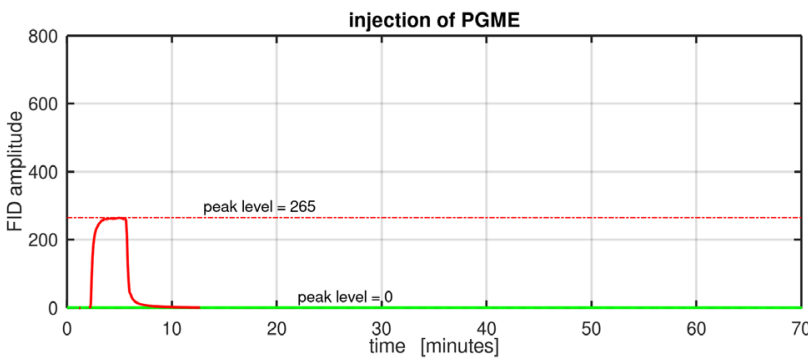

(c)

Fig. 5 FID measurements during the injection of butyl acetate (a), xylene (b) and PGME (c) at the inlet duct of the biotrickling filter (in red, single 5-minute pulse) and outlet (in green, five 5-minute pulses). The straight lines represent the peak amplitude during the solvent injection at the inlet (in red) and the outlet (in green). These went into Eq. (1)
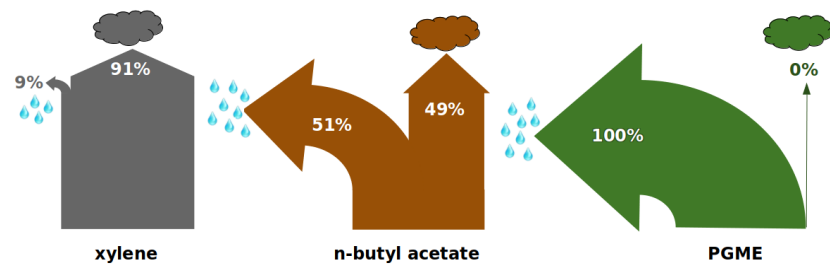

Fig. 6 Percentages of injected solvent migrating into the aqueous phase (arrows pointing to the left) and percentages exiting the biotrickling filter through the outlet (arrows pointing upwards). Numbers based on outlet/inlet peak amplitude ratios of the FID instrument during the injection of pure solvent into the biotrickling filter

\section{Results and discussion}

The injection of three individual solvents into the inlet duct of the biotrickling filter was carried out on separate days. The proportion of the solvent that is transferred into the aqueous phase is deduced from the carbon content at 
the outlet and inlet of the biotrickling filter, measured with a portable FID instrument.

\subsection{Injection of butyl acetate}

The FID instrument levels during the injection of butyl acetate into the biotrickling filter are plotted at the top of Fig. 5. In order to save solvent only a single 5-minute injection pulse with the FID instrument at the inlet was performed (red graph top of Fig. 5). Measurements at the outlet comprised 5 injection pulses (green graph top of Fig. 5). The peak amplitude of the FID instrument at the inlet during the injection of n-butyl acetate was 492 (red horizontal line top of Fig. 5) and the peak outlet amplitude on the FID instrument was 239 (green line top of Fig. 5). The fraction of butyl acetate exiting the filter amounts to $\frac{\text { FID peak amplitude at outlet }}{\text { FID peak amplitude at inlet }}=\frac{239}{492}=0.49$ or $49 \%$. Roughly $49 \%$ of the butyl acetate entering the biotrickling filter is exiting the filter at the outlet and $51 \%$ migrates into the aqueous phase.

\subsection{Injection of xylene}

The FID measurements at outlet and inlet of the biotrickling filter during the injection of xylene are plotted in the middle graph of Fig. 5. To save solvents only a single 5-minute injection pulse with the FID instrument at the inlet was performed, whereas the outlet measurements consisted of five injection pulses. The peak amplitude of the FID instrument at the inlet was 745 (red line middle of Fig. 5). The peak outlet amplitude on the FID instrument is 677 (green line middle of Fig. 5). The fraction of xylene exiting the

filter amounts to $\frac{\text { FID peak amplitude at outlet }}{\text { FID peak amplitude at inlet }}=\frac{677}{745}=0.91$ or $91 \%$. Gas-to-liquid transfer of xylene is extremely limited and almost all of the injected xylene is leaving the biotrickling filter at the outlet.

\subsection{Injection of PGME}

Measured FID levels at the inlet and outlet of the biotrickling filter during the injection of PGME are plotted into the bottom graph of Fig. 5. Again, in order to save solvents only a single 5-minute injection pulse with the FID instrument at the inlet was performed. Analogous to the two previous experiments, the outlet measurements consisted of five 5-minute long injection pulses with 10-minute breaks between them. The peak amplitude during PGME injection was 265 (carbon) units (red line at the bottom of Fig. 5). The PGME output amplitude was zero, and the fraction of PGME exiting the filter is $\frac{\text { FID peak amplitude at outlet }}{\text { FID peak amplitude at inlet }}=\frac{0}{265}=0$ or $0 \%$. It is clear that PGME is dissolving into the aqueous phase extremely well and gas-liquid mass transfer of PGME is dramatic. No PGME appears to be exiting the biotrickling filter through the outlet. From the FID amplitudes measured with butyl acetate and xylene some FID signal at the outlet of the biofilter was expected. However, when PGME was injected into the filter inlet duct, no signal was detected on the FID instrument at the filter outlet as shown in the green graph at the bottom of Fig. 5. The FID instrument was checked for malfunctioning and it was moved to the filter inlet on the same day to successfully measure the inlet amplitude during the injection of a single 5-minute PGME pulse. PGME behaves completely different to the previous two solvents - peak amplitude at the outlet is zero or below the detection limit of the instrument. Virtually no PGME arrives at the outlet of the biotrickling filter. Instead, all injected PGME is migrating into the aqueous phase inside the filter.

The FID instrument amplitude ratios between outlet and inlet indicate the extent of dissolution of the three solvents into the liquid phase. These peak amplitude ratios were used to produce Fig. 6 with Eq. (1). The VOC concentration in the circulation liquid is initially zero but is gradually increasing with the number of injections and the increasing VOC concentration in the circulation liquid was measured using headspace gas chromatography (data not shown). It is assumed that desorption (from the aqueous back into the gaseous phase) does not play a role within the 30-minute experiment. Desorption effects could possibly be observed by measuring either VOC concentration in the circulation liquid over hours or days after the injection or in the exhaust funnel using the FID instrument. The latter option would benefit from a reduction of the $15000 \mathrm{~m}^{3} \mathrm{~h}^{-1}$ air flow rate to increase the (probably rather low) VOC concentration in the exhaust air from desorption.

\subsection{Limitations}

In this study approximate transfer from the gaseous into the aqueous phase for three solvents with widely differing Henry's law solubility constants were measured in-situ. Pure solvents were injected into the abiotic biotrickling filter inlet duct with biofilm absent. Biofilm, however, unlike pure water, consists of complex organic material such as 
living cells, proteins, lipids, EPS (extracellular polymeric substances), DNA, 3-dimensional spaces and water channels $[52,53]$. Even if a large proportion of active biofilm is indeed water, the mass transfer in the two cases:

1. absence and

2. presence of a biofilm is likely to be different.

The rather severe mass transfer limitation of aromatic, hydrophobic solvents such as xylene, observed here in the absence of a biofilm may improve if a biofilm is present. Yet little is known about the degree of improvement, even though the issue was occasionally pointed out [54]. Similarly, extracellular polymeric substances (EPS) may possess both hydrophobic and hydrophilic properties [55]. If and to what degree the presence of a biofilm in a biotrickling filter improves mass transfer of hydrophobic solvents such as xylene, still remains speculation.

\section{Summary and conclusions}

Three aqueous solvation experiments were carried out on a full-scale, but abiotic biotrickling filter with biofilm absent. The filter was designed for the removal of solvents from an industrial paint shop floor and three common VOCs with widely differing hydrophilic properties (n-butyl acetate, xylene, PGME) were individually injected into the inlet duct of the biotrickling filter, and driven through the filter by an electric fan using ambient air. During the injection, gaseous carbon concentrations at outlet and inlet of the biotrickling filter were measured with a portable FID instrument. Based on these measurements the following conclusions can be drawn:

- FID instrument: If pure solvents are injected into the inlet duct, a FID instrument is perfectly able to measure the carbon load at the inlet and outlet of the filter. As expected, outlet solvent levels are more fluctuating compared to inlet levels.

- n-butyl acetate: Is moderately migrating into the aqueous phase. The FID amplitude at the filter outlet amounts to less than half the inlet amplitude (top of Fig. 5). Approximately $51 \%$ of the injected butyl

\section{References}

[1] Garner, L. G., Barton, T. A. "Biofiltration for abatement of VOC and HAP emissions", Metal Finishing, 100(11-12), pp. 12-18, 2002. https://doi.org/10.1016/S0026-0576(02)80931-X

[2] Mathur, A. K., Majumder, C. B. "Biofiltration and kinetic aspects of a biotrickling filter for the removal of paint solvent mixture laden air stream", Journal of Hazardous Materials, 152(3), pp. 1027-1036, 2008. https://doi.org/10.1016/j.jhazmat.2007.07.112 acetate migrates into the aqueous phase and $49 \%$ exits the filter again via the outlet (middle graph of Fig. 6).

- xylene: On top of low biodegradability issues with this solvent, xylene hardly migrates into the aqueous phase. Approximately $91 \%$ of the xylene going into the filter is leaving the filter (Fig. 5). This solvent presents a serious biodegradation problem - it cannot be metabolized by microorganisms if it is not migrating into the aqueous phase.

- PGME: Fully enters the aqueous phase in line with the high Henry's law solubility constant for this solvent. The FID amplitude at the outlet is zero (green graph bottom of Fig. 5).

The wellknown, highly hydrophobic behavior of nonpolar solvents such as xylene can clearly be observed in a large-scale, industrial biotrickling filter. Forcing a nonpolar, hydrophobic solvent gas/aerosol such as xylene through the dense packing at high speed does obviously not improve the transfer into the aqueous phase. Gaseous, hydrophobic solvents hardly migrate into the aqueous phase and therefore are hard to biodegrade in a biotrickling filter. Inadequate gas-to-aqueous phase transfer is obviously the reason for the malperformance of industrial biotrickling filters when mixed solvents are treated. The data reported here together with associated the GNU Octave *.m files used to produce Fig. 5 are at [56] in accordance with open science guidelines (e.g. [57]).

\section{Acknowledgement}

This study was funded by a 2-year research grant from the German Federal Ministry for Economic Affairs and Energy [58] from 2018 to 2020. The company Holzammer Ltd. [59], in particular the head of their coating department, Martin Vieracker, and managing director Mathias Holzammer allowed access and measurements on their biotrickling filter. Warnecke and Böhm Coating [40] supplied pure, industrial solvents free of charge. Oscar Scharf (BSc) was assisting on site.

[3] Hahne, J. "Development of exhaust air treatment in animal husbandry in Germany", Landtechnik, 66(4), pp. 289-293, 2011. https://doi.org/10.15150/1t.2011.413

[4] Melse, R. W., Mol, G. "Odour and ammonia removal from pig house exhaust air using a biotrickling filter", Water Science and Technology, 50(4), pp. 275-282, 2004. https://doi.org/10.2166/wst.2004.0283 
[5] Sakuma, T., Jinsiriwanit, S., Hattori, T., Deshusses, M. A. "Removal of ammonia from contaminated air in a biotrickling filter - Denitrifying bioreactor combination system", Water Research, 42(17), pp. 4507-4513, 2008. https://doi.org/10.1016/j.watres.2008.07.036

[6] Gerl, T., Engesser, K.-H., Dobslaw, D. "Bioabbaubarkeit von 2-Ethylhexylacetat, Methylisobutylketon und Methylethylketon in Biotricklingfiltern", Chemie Ingenieur Technik, 87(7), pp. 931-939, 2015.

https://doi.org/10.1002/cite.201400067

[7] McNevin, D., Barford, J. "Biofiltration as an odour abatement strategy", Biochemical Engineering Journal, 5(3), pp. 231-242, 2000.

https://oi.org/10.1016/s1369-703x(00)00064-4

[8] Schlegelmilch, M., Streese, J., Stegmann, R. "Odour management and treatment technologies: An overview", Waste Management, 25(9), pp. 928-939, 2005.

https://doi.org/10.1016/j.wasman.2005.07.006

[9] Malhautier, L., Khammar, N., Bayle, S., Fanlo, J.-L. "Biofiltration of volatile organic compounds", Applied Microbiology and Biotechnology, 68(1), pp. 16-22, 2005.

https://doi.org/10.1007/s00253-005-1960-z

[10] Kumar, T. P., Mathur, Kumar, M. A., Chandrajit, B. "Biofiltration of Volatile Organic Compounds (VOCs) - An Overview", Research Journal of Chemical Sciences, 1(8), pp. 83-92, 2011. [online] Available at: http://isca.me/rjcs/Archives/vol1/I8/ISCARJCS-2011-174-15.pdf [Accessed: 29 April 2021]

[11] Bajpai, P. "Biological Odour Treatment", Springer, Cham, Switzerland, 2014.

https://doi.org/10.1007/978-3-319-07539-6

[12] Schiavon, M., Ragazzi, M., Rada, E. C., Torretta, V. "Air pollution control through biotrickling filters: a review considering operational aspects and expected performance", Critical Reviews in Biotechnology, 36(6), pp. 1143-1155, 2016. https://doi.org/10.3109/07388551.2015.1100586

[13] Álvarez-Hornos, F. J., Lafita, C., Martínez-Soria, V., Penya-Roja, J. M., Pérez, M. C., Gabaldón, C. "Evaluation of a pilot-scale biotrickling filter as a VOC control technology for the plastic coating sector", Biochemical Engineering Journal, 58-59, pp. 154-161, 2011. https://doi.org/10.1016/j.bej.2011.09.009

[14] Higuchi, T., Morita, Y., Minato, R. "Biofiltration of the exhaust gas contaminated by six VOC compounds for testing the feasibility of its application to a painting process", In: Proceedings of the 2010 Duke-UAM Conference on Biofiltration for Air Pollution Control, Washington, D.C., USA, 2010, pp. 273-278.

[15] Moe, W. M., Qi, B. "Biofilter Treatment of Volatile Organic Compound Emissions from Reformulated Paint: Complex Mixtures, Intermittent Operation, and Startup", Journal of the Air and Waste Management Association, 55(7), pp. 950-960, 2005. https://doi.org/10.1080/10473289.2005.10464687

[16] Paca, J., Klapkova, E., Halecky, M., Jones, K., Webster, T. S. "Interactions of hydrophobic and hydrophilic solvent component degradation in an air-phase biotrickling filter reactor", Environmental Progress, 25(4), pp. 365-372, 2006. https://doi.org/10.1002/ep.10161
[17] Qi, B., Moe, W. M., Kinney, K. A. "Treatment of Paint Spray Booth Off-Gases in a Fungal Biofilter", Journal of Environmental Engineering, 131(2), pp. 180-189, 2005. https://doi.org/10.1061/(asce)0733-9372(2005)131:2(180)

[18] Gerl, T., Engesser, K.-H., Fischer, K., Dobslaw, D. "Biologische Abluftreinigung einer Lackierabluft im Kombinationsverfahren" (Biological Waste Air Cleaning for a Dip Spinning Process Using a Combined Process), Chemie Ingenieur Technik, 88(8), pp. 1145-1150, 2016. (in German) https://doi.org/10.1002/cite.201500050

[19] Balasubramanian, P., Philip, L., Bhallamudi, M. "Biotrickling filtration of complex pharmaceutical VOC emissions along with chloroform", Bioresource Technology, 114, pp. 149-159, 2012. https://doi.org/10.1016/j.biortech.2012.03.035

[20] Hu, J., Zhang, L., Chen, J., Luo, Y., Sun, B., Chu, G. "Performance and microbial analysis of a biotrickling filter inoculated by a specific bacteria consortium for removal of a simulated mixture of pharmaceutical volatile organic compounds", Chemical Engineering Journal, 304, pp. 757-765, 2016. https://doi.org/10.1016/j.cej.2016.06.078

[21] Lan, H., Qi, S., Yang, D., Zhang, H., Liu, J., Sun, Y. "Combination of highly efficient microflora to degrade paint spray exhaust gas", Scientific Reports, 10(1), Article number: 6027, 2020. https://doi.org/10.1038/s41598-020-62972-2

[22] Dobslaw, D., Dobslaw, C., Fütterer, N., Engesser, K.-H. "Biologische Abluftreinigung von Druckereiablüften: Optimierung eines Biowäschers" (Biological exhaust air purification of printing shop exhaust air: Optimization of a bioscrubber), Chemie Ingenieur Technik, 79(10), pp. 1679-1685, 2007. (in German) https://doi.org/10.1002/cite.200700069

[23] Datta, A., Philip, L. "Biodegradation of Volatile Organic Compounds from Paint Industries", Applied Biochemistry and Biotechnology, 167(3), pp. 564-580, 2012. https://doi.org/10.1007/s12010-012-9706-8

[24] Álvarez-Hornos, F. J., Martínez-Soria, V., Marzal, P., Izquierdo, M., Gabaldón, C. "Performance and feasibility of biotrickling filtration in the control of styrene industrial air emissions", International Biodeterioration and Biodegradation, 119, pp. 329-335, 2017. https://doi.org/10.1016/j.ibiod.2016.10.016

[25] Lafita, C., Penya-Roja, J.-M., Gabaldón, C., Martínez-Soria, V. "Full-scale biotrickling filtration of volatile organic compounds from air emission in wood-coating activities", Journal of Chemical Technology and Biotechnology, 87(6), pp. 732-738, 2012. https://doi.org/10.1002/jctb.3716

[26] Martínez-Soria, V., Gabaldón, C., Penya-Roja, J. M., Palau, J., Álvarez-Hornos, F. J., Sempere, F., Soriano, C. "Performance of a Pilot-Scale Biotrickling Filter in Controlling the Volatile Organic Compound Emissions in a Furniture Manufacturing Facility", Journal of the Air and Waste Management Association, 59(8), pp. 998-1006, 2009. https://doi.org/10.3155/1047-3289.59.8.998

[27] Jobson, A., Cook, F. D., Westlake, D. W. S. "Microbial Utilization of Crude Oil", Applied Microbiology, 23(6), pp. 1082-1089, 1972. https://doi.org/10.1128/am.23.6.1082-1089.1972 
[28] Ottengraf, S. P. P., Van Den Oever, A. H. C. "Kinetics of organic compound removal from waste gases with a biological filter", Biotechnology and Bioengineering, 25(12), pp. 3089-3102, 1983. https://doi.org/10.1002/bit.260251222

[29] Deshusses, M. A., Johnson, C. T. "Development and Validation of a Simple Protocol To Rapidly Determine the Performance of Biofilters for VOC Treatment", Environmental Science and Technology, 34(3), pp. 461-467, 2000. https://doi.org/10.1021/es9909172

[30] Jacob, F., Monod, J. "Genetic regulatory mechanisms in the synthesis of proteins", Journal of Molecular Biology, 3(3), pp. 318-356, 1961. https://doi.org/10.1016/S0022-2836(61)80072-7

[31] Lessie, T. G., Phibbs, P. V. "Alternative Pathways of Carbohydrate Utilization in Pseudomonads", Annual Review of Microbiology, 38(1), pp. 359-388, 1984

https://doi.org/10.1146/annurev.mi.38.100184.002043

[32] Duetz, W. A., Marqués, S., Wind, B., Ramos, J. L., van Andel, J. G. "Catabolite repression of the toluene degradation pathway in Pseudomonas putida harboring pWW0 under various conditions of nutrient limitation in chemostat culture", Applied and Environmental Microbiology, 62(2), pp. 601-606, 1996. https://doi.org/10.1128/aem.62.2.601-606.1996

[33] Stülke, J., Hillen, W. "Carbon catabolite repression in bacteria", Current Opinion in Microbiology, 2(2), pp. 195-201, 1999. https://doi.org/10.1016/s1369-5274(99)80034-4

[34] Alvarez, J. M., Seijas, C. J., Bianchi, G. L. "Elimination of volatile organic compounds in paint drying by absorption reaction in water combined with the ozone oxidation technique", Environmental Advances, 2, Article number: 100017, 2020. https://doi.org/10.1016/j.envadv.2020.100017

[35] Cesário, M. T., Beverloo, W. A., Tramper, J., Beeftink, H. H., "Enhancement of gas-liquid mass transfer rate of apolar pollutants in the biological waste gas treatment by a dispersed organic solvent", Enzyme and Microbial Technology, 21(8), pp. 578-588, 1997. https://doi.org/10.1016/S0141-0229(97)00069-0

[36] Dumont, E., Andrès, Y., Cloirec, P. L. "Mass transfer coefficients of styrene and oxygen into silicone oil emulsions in a bubble reactor", Chemical Engineering Science, 61(17), pp. 5612-5619, 2006. https://doi.org/10.1016/j.ces.2006.04.026

[37] Dorado, A. D., Rodríguez, G., Ribera, G., Bonsfills, A., Gabriel, D., Lafuente, J., Gamisans, X. "Evaluation of Mass Transfer Coefficients in Biotrickling Filters: Experimental Determination and Comparison to Correlations", Chemical Engineering and Technology, 32(12), pp. 1941-1950, 2009. https://oi.org/10.1002/ceat.200900275

[38] Ferdowsi, M., Ramirez, A. A., Jones, J. P., Heitz, M. "Elimination of mass transfer and kinetic limited organic pollutants in biofilters: A review", International Biodeterioration and Biodegradation, 119, pp. 336-348, 2017. https://doi.org/10.1016/j.ibiod.2016.10.015

[39] Kraakman, N. J. R., Rocha-Rios, J., van Loosdrecht, M. C. M. "Review of mass transfer aspects for biological gas treatment", Applied Microbiology and Biotechnology, 91(4), pp. 873-886, 2011. https://doi.org/10.1007/s00253-011-3365-5

[40] Warnecke and Böhm Coatings Ltd. "WB coatings", [online] Available at: https://www.wb-coatings.de [Accessed: 29 April 2021]
[41] Yalkowsky, S. H., He, Y., Jain, P. "Handbook of Aqueous Solubility Data", CRC Press, Boca Raton, FL, USA, 2016. https://doi.org/10.1201/ebk1439802458

[42] Sander, R. "Compilation of Henry's law constants (version 4.0) for water as solvent", Atmospheric Chemistry and Physics, 15(8), pp. 4399-4981, 2015.

https://doi.org/10.5194/acp-15-4399-2015

[43] Institut für Arbeitsschutz der Deutschen Gesetlichen Unfallversicherung "GESTIS-Stoffdatenbank: n-Butyl acetate", [online] Available at: https://gestis.dguv.de/data?name $=013320$ [Accessed: 29 April 2021]

[44] Institut für Arbeitsschutz der Deutschen Gesetlichen Unfallversicherung "GESTIS-Stoffdatenbank: 1-Methoxy-2-propanol", [online] Available at: https://gestis.dguv.de/data?name $=071430$ [Accessed: 29 April 2021]

[45] Sata German Engineering "Sata", [online] Available at: https:// www.sata.com [Accessed: 29 April 2021]

[46] Tong, H. Y., Karasek, F. W. "Flame ionization detector response factors for compound classes in quantitative analysis of complex organic mixtures", Analitical Chemistry, 56(12), pp. 2124-2128, 1984. https://doi.org/10.1021/ac00276a033

[47] Blades, A. T. "The Flame Ionization Detector", Journal of Chromatographic Science, 11(5), pp. 251-255, 1973. https://doi.org/10.1093/chromsci/11.5.251

[48] David, D. J. "Gas chromatographic detectors", Wiley-Interscience, New York, NY, USA, 1974.

[49] Schofield, K. "The enigmatic mechanism of the flame ionization detector: Its overlooked implications for fossil fuel combustion modeling", Progress in Energy and Combustion Science, 34(3), pp. 330-350, 2008. https://doi.org/10.1016/j.pecs.2007.08.001

[50] ErsaTec GmbH "Ersatec process-analysers", [online] Available at: http://www.ersatec.com [Accessed: 29 April 2021]

[51] Calgaz" "Calgaz - Leading the World", [online] Available at: https://calgaz.com/ [Accessed: 29 April 2021]

[52] Branda, S. S., Vik, Å., Friedman, L., Kolter, R. "Biofilms: the matrix revisited", Trends in Microbiology, 13(1), pp. 20-26, 2005. https://doi.org/10.1016/j.tim.2004.11.006

[53] Flemming, H.-C., Wingender, J. "The biofilm matrix", Nature Reviews Microbiology, 8(9), pp. 623-633, 2010. https://doi.org/10.1038/nrmicro2415

[54] Miller, M. J., Allen, D. G. "Transport of hydrophobic pollutants through biofilms in biofilters", Chemical Engineering Science, 59(17), pp. 3515-3525, 2004. https://doi.org/10.1016/j.ces.2004.05.011

[55] Jorand, F., Boué-Bigne, F., Block, J. C., Urbain, V. "Hydrophobic/ hydrophilic properties of activated sludge exopolymeric substances", Water Science and Technology, 37(4-5), pp. 307-315, 1998. https://doi.org/10.2166/wst.1998.0652

[56] Gredmaier, L., Funke, P., Joachim, R., Eckert, J., GrünerLempartz, S. "Flame ionisation detector time series data from three solvents injected into an industrial, abiotic biotrickling filter that is designed to purify paint spray exhaust air", Technische Universität, München, Germany, 2021. [online] Available at: https://mediatum.ub.tum.de/1600235 [Accessed: 29 April 2021]

[57] Open AIRE "Open Scholarship", [online] Available at: https:// www.openaire.eu [Accessed: 29 April 2021] 
[58] Federal Ministry for Economic Affairs and Energy, Germany "Federal Ministry for Economic Affairs and Energy", [online] Available at: https://www.bmwi.de [Accessed: 29 April 2021]
[59] HOLZAMMER Gruppe "Hozhammer der Systempartner", [online] Available at: https://holzammer.de [Accessed: 29 April 2021] 